\title{
Deaths due to COVID-19, Lockdowns, Vaccinations and Weather Temperatures: The Case of Greece
}

\author{
By Gregory T. Papanikos"
}

\begin{abstract}
The aim of this paper is to present Greek daily descriptive statistics on confirmed deaths due to COVID-19, the days of lockdown and their effect on the number of deaths, the outcomes of vaccinations and the influence of weather temperatures. Do lockdowns work in bringing the number of deaths down? The descriptive evidence shows that this is the case even though there is a considerable lagged effect. On the other hand, vaccinations, during the time period of examination, do not seem to have diminished the number of deaths, but the reason might be that it takes time for their full effect to occur. Finally, this paper also examines the hypothesis that during the summer months the daily deaths from COVID-19 are relatively lower than during the winter months. Using average daily weather temperatures, this hypothesis cannot be falsified. Simple calculations of the functional relation between weather temperatures and deaths show that temperatures above 28.5 degrees Celsius $\left({ }^{\circ} \mathrm{C}\right)$ were associated with zero deaths.
\end{abstract}

Keywords: COVID-19, deaths, Greece, lockdown, pandemic, vaccinations, weather temperatures

\section{Introduction}

Pandemics were always here on earth along with many other natural disasters. ${ }^{1}$ They come and go. Historically, the most famous pandemic was the plague which hit Athens in 430 BCE (Papanikos 2021b). Since then, pandemics have appeared many times in history. As in ancient Athens, these pandemics have had harmful effects on the economy, society, demographics (population) and ethics. ${ }^{2}$

The current pandemic is not an exemption. Individuals' and states' reactions to COVID-19 are no different from the individual, social and political reactions of the pandemic that hit Athens 2,500 years ago. That plague lasted for three years before it disappeared altogether as so eloquently all of these are described by Thucydides in his work on The Peloponnesian War. I have examined elsewhere these issues, including Thucydides' account of the ancient plague and the European

\footnotetext{
"President, Athens Institute for Education and Research, Greece.

${ }^{1}$ Wars, as mentioned by Hesiod's magnum opus Works and Days, are the worst of all disasters, but these are man-made disasters and not natural ones. One may also argue that the deleterious effects of natural disasters depend, to a certain extent, on human actions and behaviors.

${ }^{2}$ Not all effects are detrimental though. Pandemics may force the humanity to invest into new pharmacies which might have more general beneficial applications. On the other hand, pandemics, similar to wars, have produced some of the best-known works in literature, e.g., The Decameron (1353) by Giovanni Boccaccio; A Journal of the Year of the Plague (1720) by Daniel Defoe; The Plague (1947) by Albert Camus and many others. Without a real pandemic, these works might not have been written, and all future generations would have lost the opportunity to read these masterpieces. If reading good pieces of literature is an investment in human capital, as I believe it is, then one must compare the cost of the pandemic with all these losses of human capital of all future generations.
} 
Union's efforts to harmonize economic and social policies to cope with COVID19 (Papanikos 2020a, 2020b, 2020c, 2020d, 2021a, 2021b). Examples of economic and social policies are the recovery plans currently implemented by the European Union, the vaccine distribution channels organized at the European Union-level and the establishment of a European vaccination passport.

Since the pandemic struck the world in late 2019 and in early 2020, another "pandemic" infected the world of academics, i.e., writing about the COVID-19 itself. In just one year, the literature on COVID-19 has mushroomed. All aspects of the current pandemic have been examined. The theme "infected" all academic disciplines and the "cases of these infections" are multiplied at a geometric rate. As a matter of fact, I was one of the first infected and started writing and publishing on the issue of COVID-19.

The Athens Institute for Education and Research (ATINER) received quite a few dozens of papers either to be considered for presentations at one of its many small academic events organized throughout the year, and/or to be considered for publication in one of its journals. This time, the presentations were done remotely thanks to Prometheus, who provided the technology. In just a few months, those who had the property rights in these technologies became billionaires. Who says that COVID-19 had only negative effects? For some people, the pandemic was a blessing.

Papers accepted for publication in one of ATINER's journals examined the economic aspects of the pandemic (Adejare et al. 2021, Jones and Comfort 2020, Uwah et al. 2021); the health and medical aspects (Parodi et al. 2021, Uysal et al. 2020); the social dimensions (Bäckman 2021, De Falco et al. 2021, Jurić 2021); the communication facets (Mengu et al. 2021, Osisanwo 2021); the legal implications (Marchetti 2021); and the educational adjustments (Güvercin et al. 2021, Kılıç 2021, Pinchbeck and Heaney 2021). Of course, these do not exhaust the literature, but here they are given as examples of the types of studies written to account for the unexpected phenomenon of COVID-19. Unexpected not in terms of the occurrence of the event, which is unavoidable, but of its exact timing. Those who claim that they have predicted the coming of a pandemic, they simply meant that pandemics will re-appear again in the future. Prognosis and prediction, in order to be useful, must include the time framework of the event. Otherwise, it has the same value as the prognosis that one day we will all die from something.

It goes beyond the scope of this short paper to review this huge literature. The purpose of this study is to examine some preliminary empirical evidence of the effects of lockdowns, vaccinations and weather temperature variations on the daily death outcomes of COVID-19 in Greece. Since this is an ongoing process, the descriptive statistical evidence and the results should be interpreted with caution. This is of particular significance when the effects of vaccinations are analyzed. Their expected positive influence in reducing the daily number of deaths will take time to materialize, and currently we are in the beginning of the process. After a few months and when all lockdown measures are completely lifted, then the full effect of vaccinations can be appraised. I should point out at the outset that the discussion, primarily the one on the effects of vaccinations, relate to short run 
outcomes (less than a year). Nobody knows the medium or long run effects of COVID-19 immunization, or of the disease itself.

In this exploratory study, Greek data are used primarily because of my familiarity with the current developments in the country. It is really very difficult to evaluate policy effects if the researcher does not have a knowledge and a feeling of the social and cultural environment. Nevertheless, my interpretation of this environment may not be appropriate and could become an issue of dispute. Looking at the effects in only one country has its own benefits as well because other concurrent influences can be isolated. This may include the quality and the quantity of health and hospital services; weather conditions; sociocultural attitudes in accepting and implementing such policies as lockdowns; social distancing; and attitudes towards vaccinations. Cross-country studies have their merits in comparing the efficiency and the effectiveness of various policy interventionsthis is not examined in this paper. In another paper, I have compared national health expenditures in the European Union and their effects on COVID-19 (Papanikos 2020c, 2020d).

This paper is organized as follows. The next section discusses the three Greek lockdowns implemented by the government as urgent measures to cope with the spread of the pandemic. The following section of the paper analyzes the number of daily deaths from COVID-19, taken into consideration the three lockdown periods. Thus, this section provides preliminary evidence on the effects of lockdowns on the number of daily deaths due to COVID-19. The fourth section looks at the effect of vaccinations (both the number of vaccinations and the number of people vaccinated) on daily deaths. The fifth section relates daily average weather temperatures to COVID-19 daily deaths. The final section concludes, including some ideas of the direction of future research.

\section{Coping with the Pandemic: The Lockdown Days}

The Greek government responded quickly to the pandemic and locked down the economy even before any death was reported (Figure 1). It also took a number of additional measures, but the most important ones were the partial closing down of the economy, the online provision of education (private and public) and the cancelling of all cultural, religious and sporting events. Practically what these measures aimed at was to restrict social interactions by requesting people to stay home; this was not entirely unique to Greece. With very few exceptions, many other countries in the world implemented exactly the same policies. There were additional measures such as communication policies to persuade the public to follow, on a voluntary basis, certain rules related to personal hygiene, wearing masks everywhere (it became mandatory during the last two lockdowns) and keep social distancing as often as possible. However, these are secondary measures because if someone is restricted at home, then personal hygiene and social distancing become irrelevant. These polices are not reviewed in this study.

In Greece, the lockdown of the economy begun on 11 of March 2020 (Table 1). Some of these measures are still in existence today; some have never been 
lifted, e.g., attending sports and cultural events. However, for the purpose of this study, a distinction is made between a mild and a strong version of a lockdown. The demarcation line is whether primary and secondary schools were open or not. Thus, Figure 1 makes a distinction between restrictive lockdowns and not-sorestrictive lockdowns.

Figure 1. Days of Lockdown due to COVID-19 from 26 Feb 2020 to 14 Jun 2021

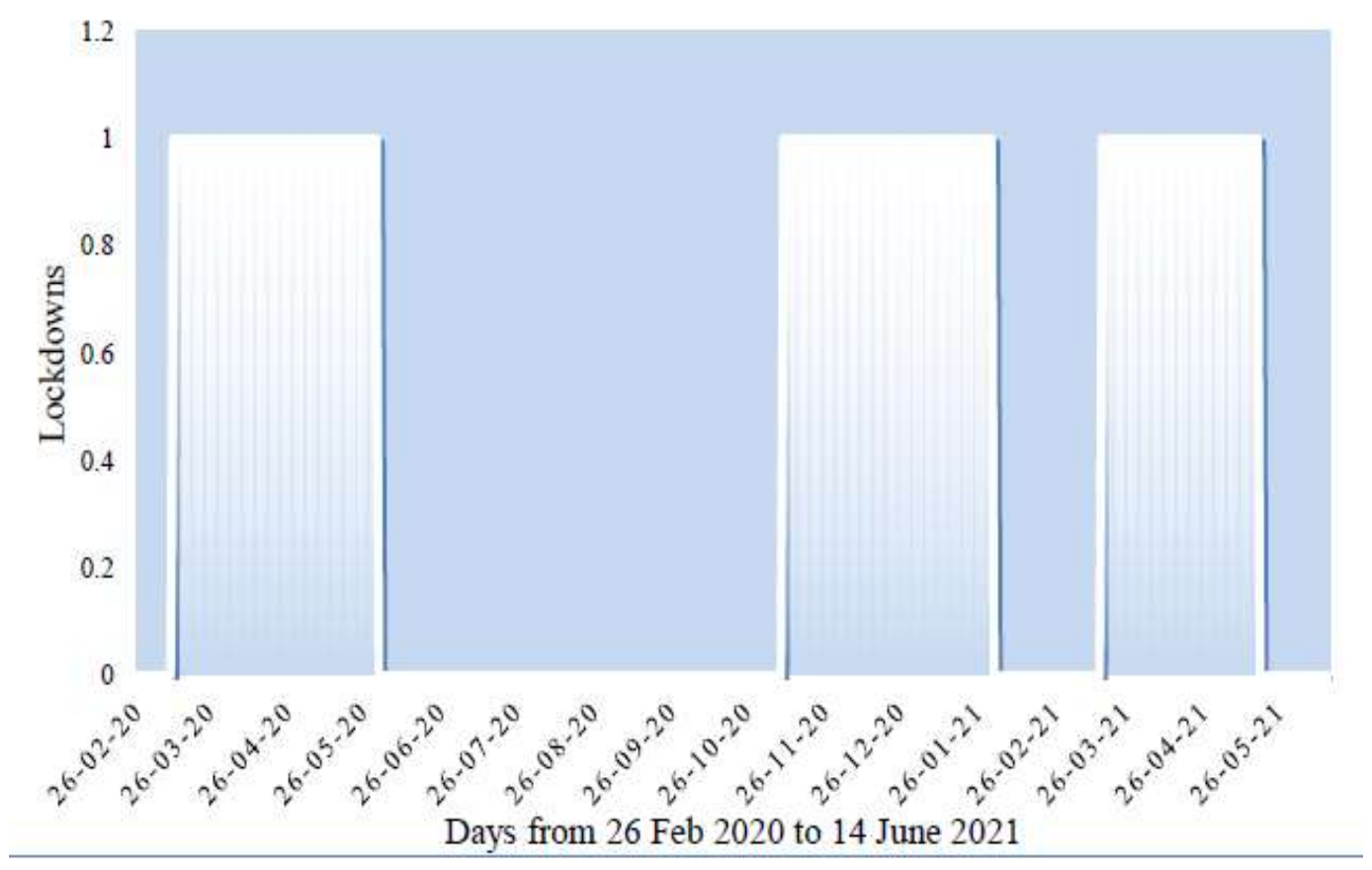

Figure 1 shows that during the period of the current pandemic, the Greek government had decided to close down the economy three times. Table 1 reports the starting and the ending days of each of the three lockdowns and their duration in days. The first lockdown started on 11 of March 2020 and lasted 82 days until the 31 of May 2020. The second lockdown was the longest; it lasted 84 days, starting on 9 of November 2020 and ended on 31 of January 2021. The last lockdown started on 16 of March 2021 and ended on 17 of May 2021, a duration of 63 days.

Table 1. Lockdowns

\begin{tabular}{|l|c|c|c|}
\hline Lockdowns & First Day & Last Day & Duration in Days \\
\hline 1 & 11 March 2020 & 31 May 2020 & 82 \\
\hline 2 & 9 November 2020 & 31 January 2021 & 84 \\
\hline 3 & 16 March 2021 & 17 May 2021 & 63 \\
\hline
\end{tabular}

Note: The dates were gathered from various Greek government announcements.

During this long period of 475 days, the economy was under a strict lockdown for almost half of the period, 229 days or $48 \%$ of the total days. The question is whether these three lockdowns had any positive effect in decreasing the number of deaths. An actual comparison is impossible because one should estimate what 
would have been the number of deaths without any lockdown. In addition, only the short run (immediate) effects of lockdowns are examined. In the medium and long runs, the effects on the number of deaths might be different. The total number of deaths due to COVID-19 in Greece is examined in the following section.

\section{Deaths from the Pandemic}

There are many ways to measure the effects of COVID-19. The number of people infected is an obvious indicator, but, unfortunately, reliable data on this variable are not available. The reason is that there are many people who had been infected without any symptoms at all; this is truer for young people. These people went unnoticed and are not reported anywhere to be found. Thus, the number of people infected cannot be used as an indicator of the impact of COVID-19. A more accurate indicator is the number of people who died from the disease, but still this is a complicated index because many deaths may be attributed to COVID19, even though these people died for other reasons as well; the so-called underlying medical conditions. In Greece most of the people who died from COVID-19 were otherwise too old and suffering from a chronic disease. Notwithstanding, this is a good indicator when the analysis is done for one particular country. When comparisons are made between countries then this indicator may not be appropriate because the total number of deaths due to COVID-19 are affected by the level of socioeconomic development. These countries are able to provide better (in quality and quantity terms) public and private health and hospital services.

In an earlier study (Papanikos 2020a), I found that social spending did matter. The higher the social spending as a share of GDP, the lower the ratio of deaths to population. It seems that social policy, which includes health spending, does reduce the death rate. Similarly, the size of population played a role. Population size had a non-linear impact on deaths due to COVID-19. Highly populated countries were hit harder by COVID-19, but the rate of the effect decreased as population size increased.

In this current study, these effects are not relevant because only one country is examined and consequently the total number of deaths is considered as the appropriate variable to use. Figures 2 and 3 depict (a) the daily number of deaths due to COVID-19 and (b) the accumulated number of deaths due to COVID-19 from the first day of the first case of an infected person reported on 26 February 2020. The first reported death was on 12 March 2020. 
Vol. 8, No. 3 Papanikos: Deaths due to COVID-19, Lockdowns, Vaccinations and ...

Figure 2. Daily Number of Deaths due to COVID-19 from 26 Feb 2020 to 14 Jun 2021

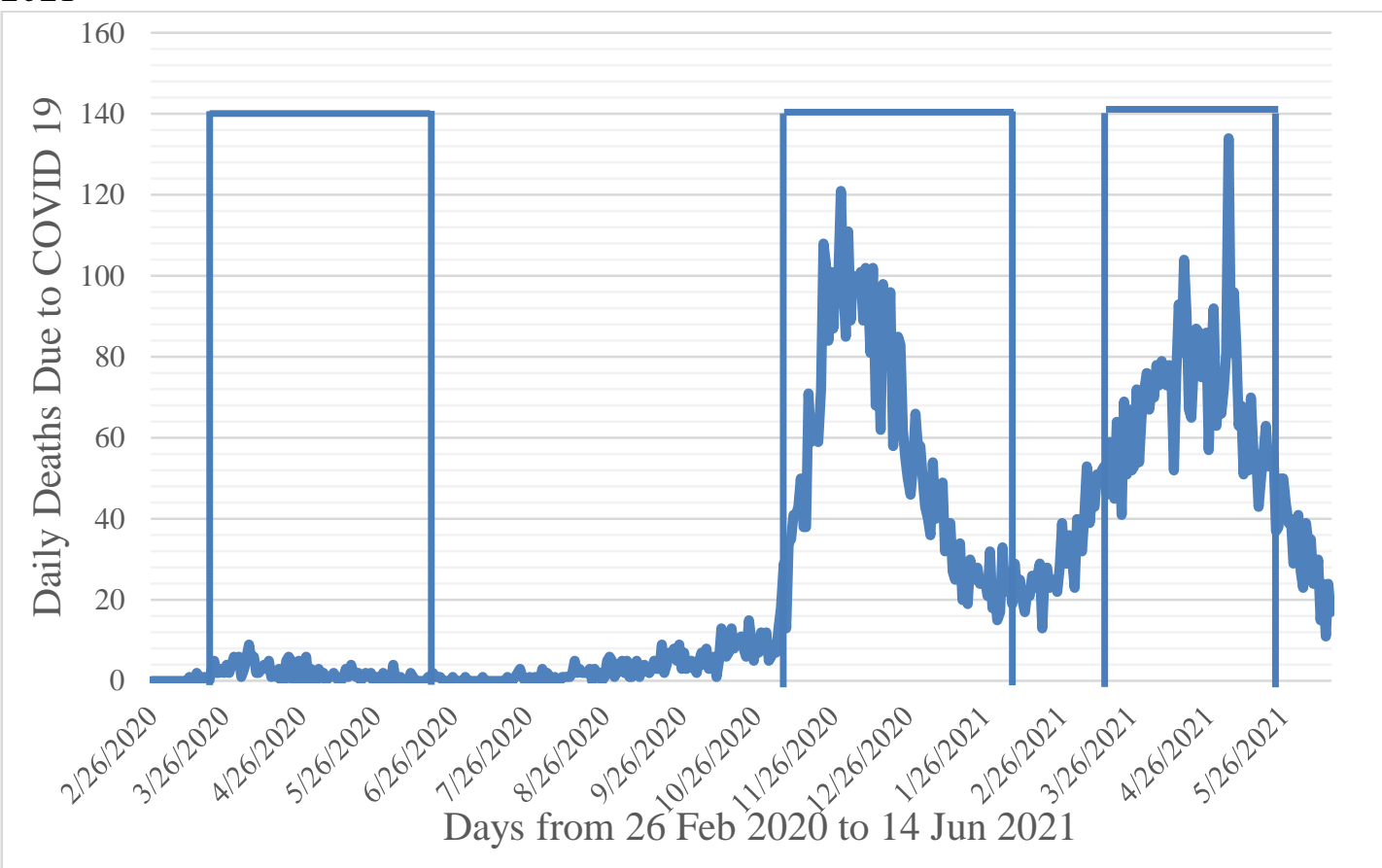

Figure 3. Accumulated Deaths due to COVID-19 from 26 Feb 2020 to 14 Jun 2021

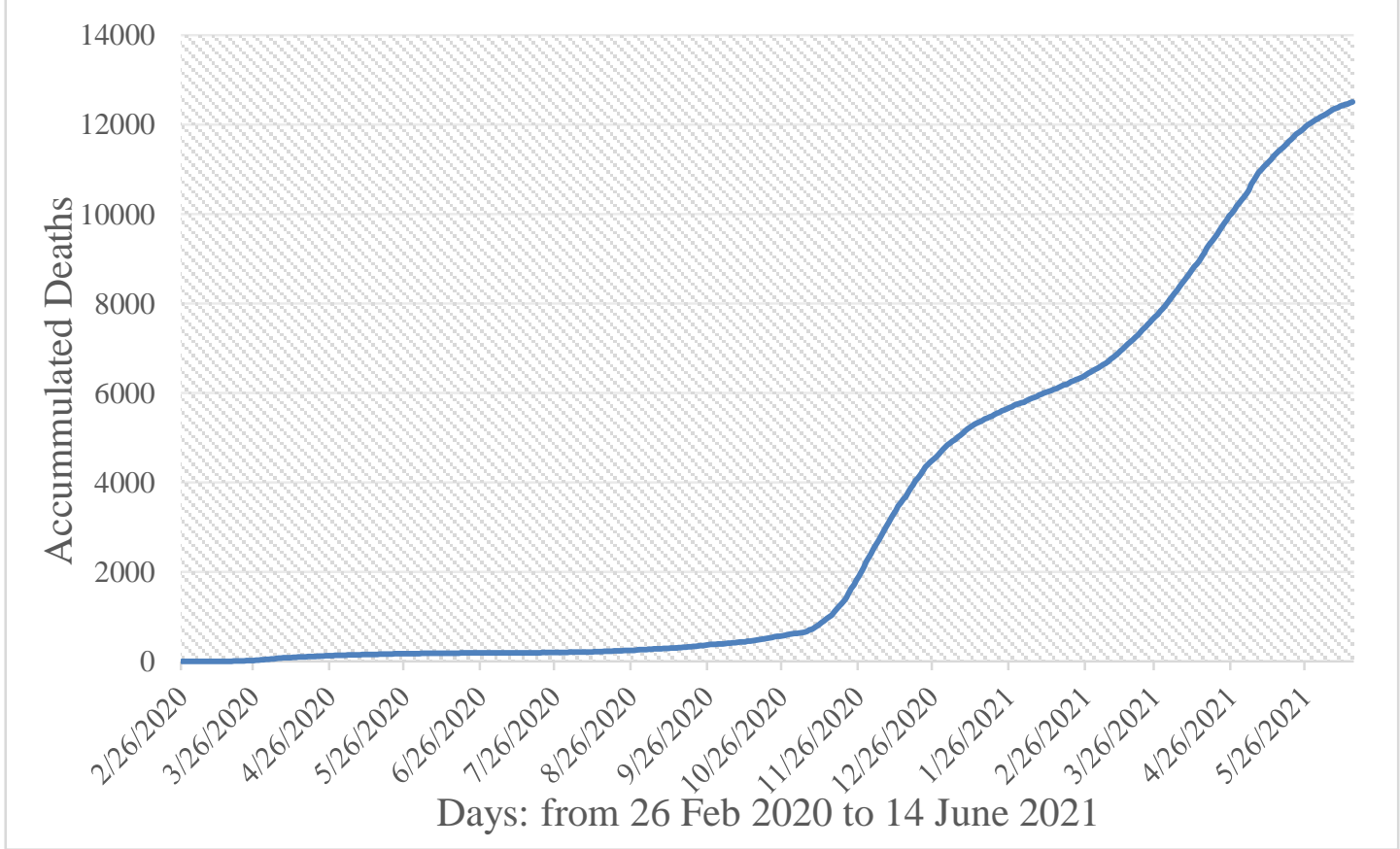

As already mentioned, the government locked down the economy the day before, on 11 of March 2020. During the 82 days of the first lockdown the average reported daily number of deaths was 2.1 people. At the end of the first lockdown the accumulated number of deaths had stabilized, i.e., the curve flattened out 
(Figure 3). The lockdown periods are embedded in Figure 2 as three orthogonal parallelograms with the length of the base being determined by the number of days of its duration. The height does not indicate anything.

The government was forced to open up the economy because of the huge revenue loss from international tourism non-arrivals. The economy remained open throughout the tourism season from the beginning of May of 2020 until the first week of November of 2020. There were 187 days of no strict lockdown. During this period, the average daily number of deaths was only three. The government decided to lockdown the economy again for the second time for a duration of 84 days (Table 1) until the economy opened again on 31 January of 2021, but, pretty soon, a third lockdown was implemented on 16 March 2021 for 63 days. The economy opened up again for the 2021 tourism season. Figure 3 shows that the total (accumulated) number of deaths from COVID-19 on 14 of June 2021 was 12,503 people.

What were the effects of lockdowns on the daily number of deaths? Figure 2 shows that the first lockdown had a drastic effect of keeping the daily number of deaths very low indeed. This low number of deaths continued throughout the summer months even though the strict lockdown measures were lifted, but this might have been the effect of higher weather temperatures as shown in the fifth section of this paper.

By the end of October 2020, the total number of daily deaths was starting to rise again which alarmed the Greek authorities to enforce a second lockdown. In the beginning of the second lockdown, the number of deaths skyrocketed because of a lagged epidemiological effect. During the Christmas holiday period some measures were lifted, but the schools were closed because of the holidays. This might explain the spike in deaths in the third week of December 2020. After the holidays, the lockdown was working again. The daily death toll of COVID-19 decreased, but had never returned to its earlier period of the first lockdown.

There appears to be two explanations to account for this difference. Firstly, the government itself did not implement the lockdown with the same zeal as it did during the first lockdown. Secondly, people were really tired of being locked in. Unlike in the first lockdown, this time they did not demonstrate the same obedience and patience.

Things became worse during the third lockdown from 16 of March 2021 to 17 May 2021 (63 days in total). Comparing the two last lockdowns, some important differences are observed. Firstly, the average, the standard deviation and the maximum values of the number of deaths were higher in the third lockdown compared to the same numbers of the second lockdown. Secondly, it took a longer time for the effects of the third lockdown to show up. Thirdly, by the end of the third lockdown, the effect of vaccinations may have become operative as shown in the next section. Thus, with a scatter diagram the two effects cannot be separated. There is a need to develop a regression model to estimate the two separate effects. This is not undertaken in the current study.

An important issue is not only the total number of deaths, but their distribution over time. Table 2 tabulates the daily distribution of deaths in Greece during the period of the pandemic into 14 categories over ten days. This is 
important information because it relates to peak load demand which is usually applied in energy demand, but applies to hospitalizations as well.

Table 2. Tabulation of Daily Deaths from 26 Feb 2020 to 14 Jun 2021

\begin{tabular}{|l|c|c|c|c|}
\hline Value & & & Cumulative & Cumulative \\
\hline$[0,10)$ & Count & Percent & Count & Percent \\
\hline$[10,20)$ & 242 & 50.95 & 242 & 50.95 \\
\hline$[20,30)$ & 23 & 4.84 & 265 & 55.79 \\
\hline$[30,40)$ & 43 & 9.05 & 308 & 64.84 \\
\hline$[40,50)$ & 27 & 5.68 & 335 & 70.53 \\
\hline$[50,60)$ & 22 & 4.63 & 357 & 75.16 \\
\hline$[60,70)$ & 34 & 7.16 & 391 & 82.32 \\
\hline$[70,80)$ & 20 & 4.21 & 411 & 86.53 \\
\hline$[80,90)$ & 23 & 4.84 & 434 & 91.37 \\
\hline$[90,100)$ & 18 & 3.79 & 452 & 95.16 \\
\hline$[100,110)$ & 11 & 2.32 & 463 & 97.47 \\
\hline$[110,120)$ & 9 & 1.89 & 472 & 99.37 \\
\hline$[120,130)$ & 1 & 0.21 & 473 & 99.58 \\
\hline$[130,140)$ & 1 & 0.21 & 474 & 99.79 \\
\hline Total & 1 & 0.21 & 475 & 100.00 \\
\hline & 475 & 100.00 & 475 & 100.00 \\
\hline
\end{tabular}

What is important here is not so much the average daily number of deaths, but their daily variations. Half of the first 475 days of the pandemic had less than 10 deaths per day which was easily handled by the Greek health and hospital sector. Not shown in the table are the values of the average of 26 deaths and the standard deviation of 31 deaths. It is the latter statistic that is of concern here. If the standard deviation was zero, the number of 26 deaths each day would be easily handled by the Greek hospital sector. Having more than 50 deaths per day was worrisome and put a lot of pressure on the health and hospital sector. This occurred $25 \%$ of the days of the pandemic period. This put a lot of strain on the hospital services and especially in the intensive care units of them.

\section{Vaccinations and the Daily Number of Deaths due to COVID-19}

This section examines the effect of the total number of vaccinations and the total number of people vaccinated on the daily number of deaths (Figures 4, 5 and 6). As shown in the previous section, the Greek government did an outstanding job in implementing the first lockdown with excellent outcomes in terms of the daily number of deaths due to COVID-19. It did not perform as well in the second and the third lockdowns for the two reasons already mentioned.

However, a new tool was discovered to be used by national policy makers to fight the pandemic. Prometheus stole the secret of vaccines held by the Olympians and started to distribute it to the world - not so equally as Prometheus himself would have liked it to have been, but, at least, it was available. The Greek government did an excellent job in organizing the vaccination program which had 
received many positive remarks from international media and other governments. Figure 4 shows the number of new vaccinations performed every day. The vaccination program started on 28 of December 2020 when 447 people were vaccinated. This figure was over 100 thousand in the first days of June 2021. The steepness of the regression line of Figure 4 shows that vaccinations were increasing at a very high rate.

Figure 4. Number of New Vaccinations per Day from 28 Dec 2020 to 14 Jun 2021

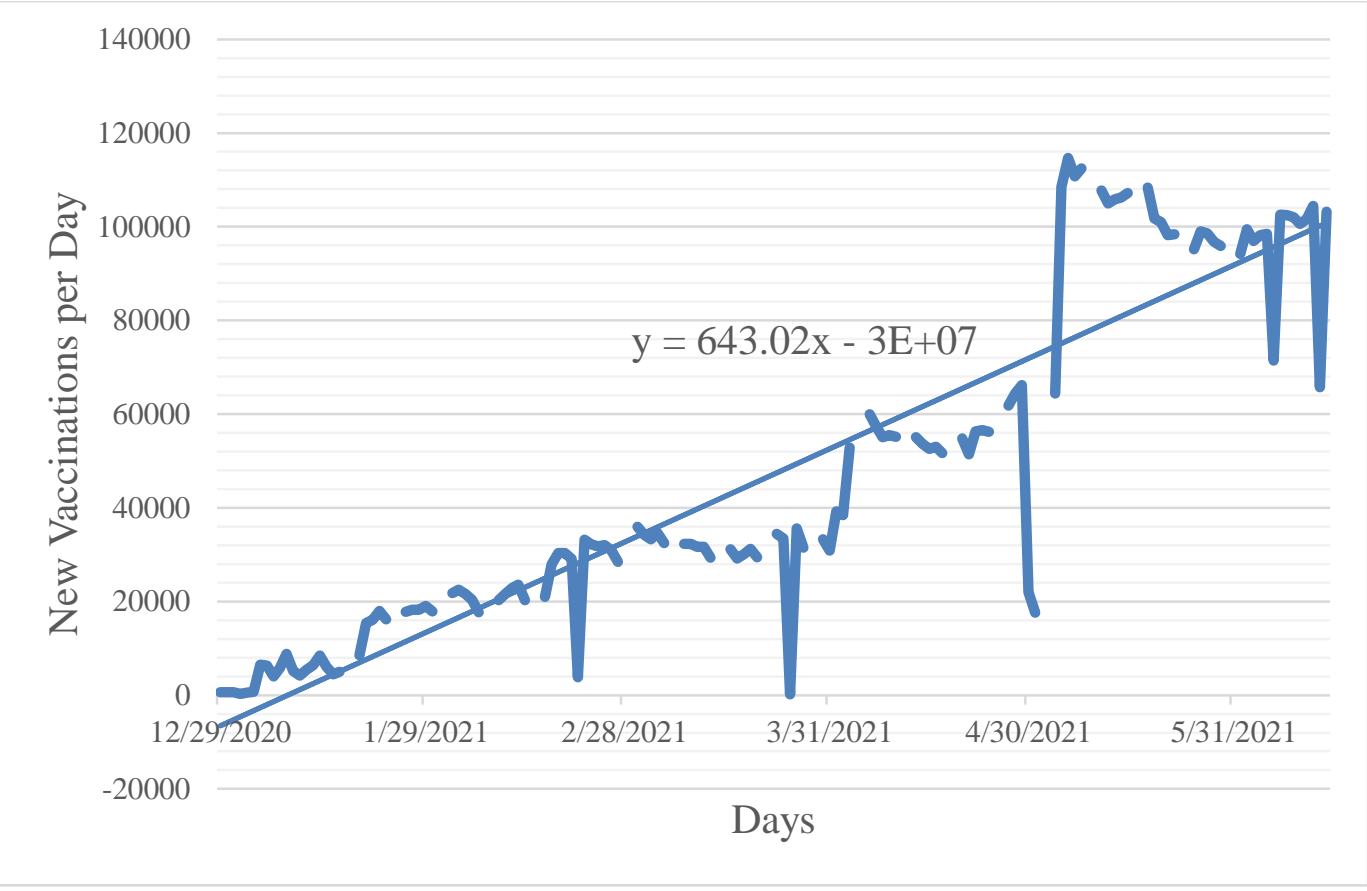

Note: This graph does not include the days with zero vaccinations to avoid cluttering.

Figure 5. Total Number of Vaccinations and Daily Deaths due to COVID-19 from 26 Feb 2020 to 14 Jun 2021

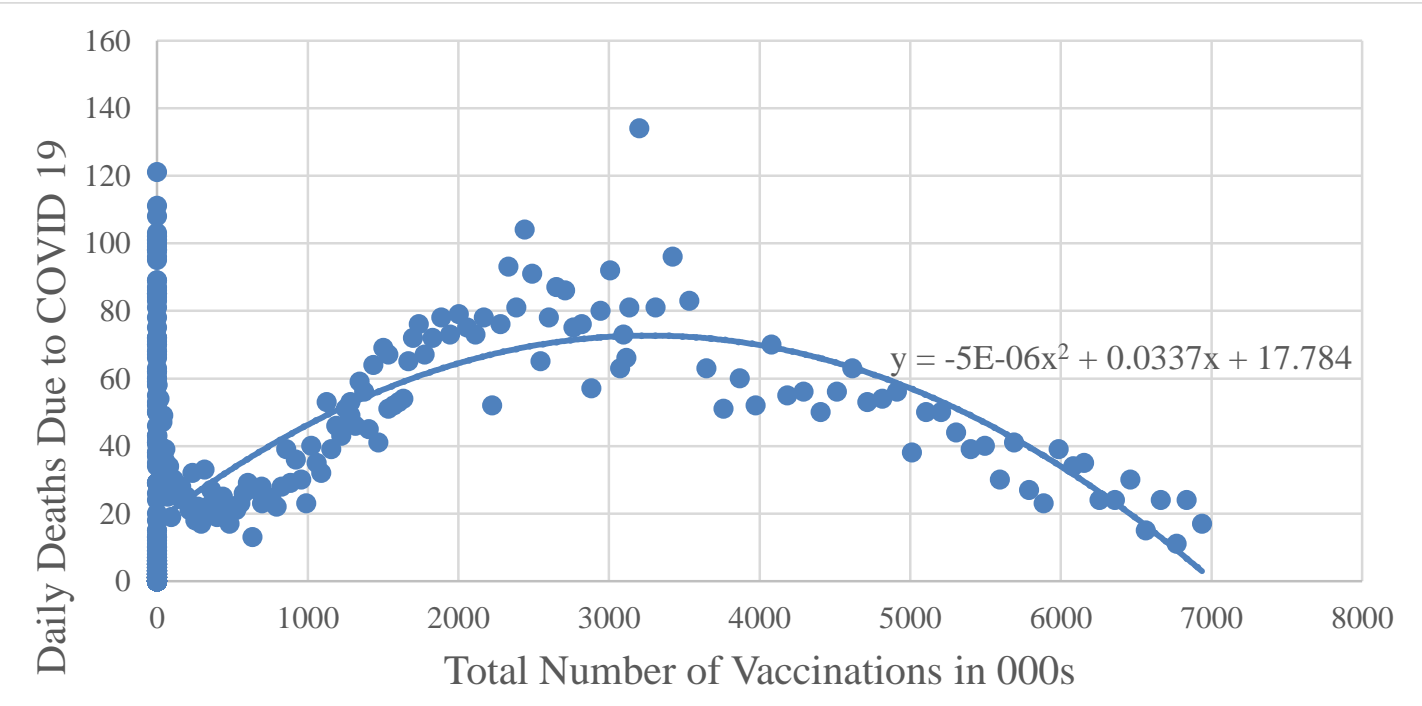


By the end of the period (14 June 2021), the total number of vaccinations were $6,938,959$ and the total number of people vaccinated was $4,274,435$. What was the effect on the number of deaths due to COVID-19? In this paper, simple correlations are used as these are shown in a scatter diagram. They do not imply causality, but this is easily inferred from epidemiology. In the first days after the vaccination, people are still vulnerable to catching the disease. If they relax their precautionary measures, then they increase their probability of being infected. At the aggregate (society's) level, this will show as an increase in the deaths due to COVID-19 among people who were recently vaccinated until a few weeks have passed, in order for people to develop the necessary antibodies to immunize from the disease - and still then, nobody is $100 \%$ protected. If this is the case, we might get a non-linear effect of vaccinations; a positive in the beginning and a strong negative thereafter.

Figure 6. Total Number of People Vaccinated and Daily Deaths due to COVID-19 from 26 Feb 2020 to 14 Jun 2021

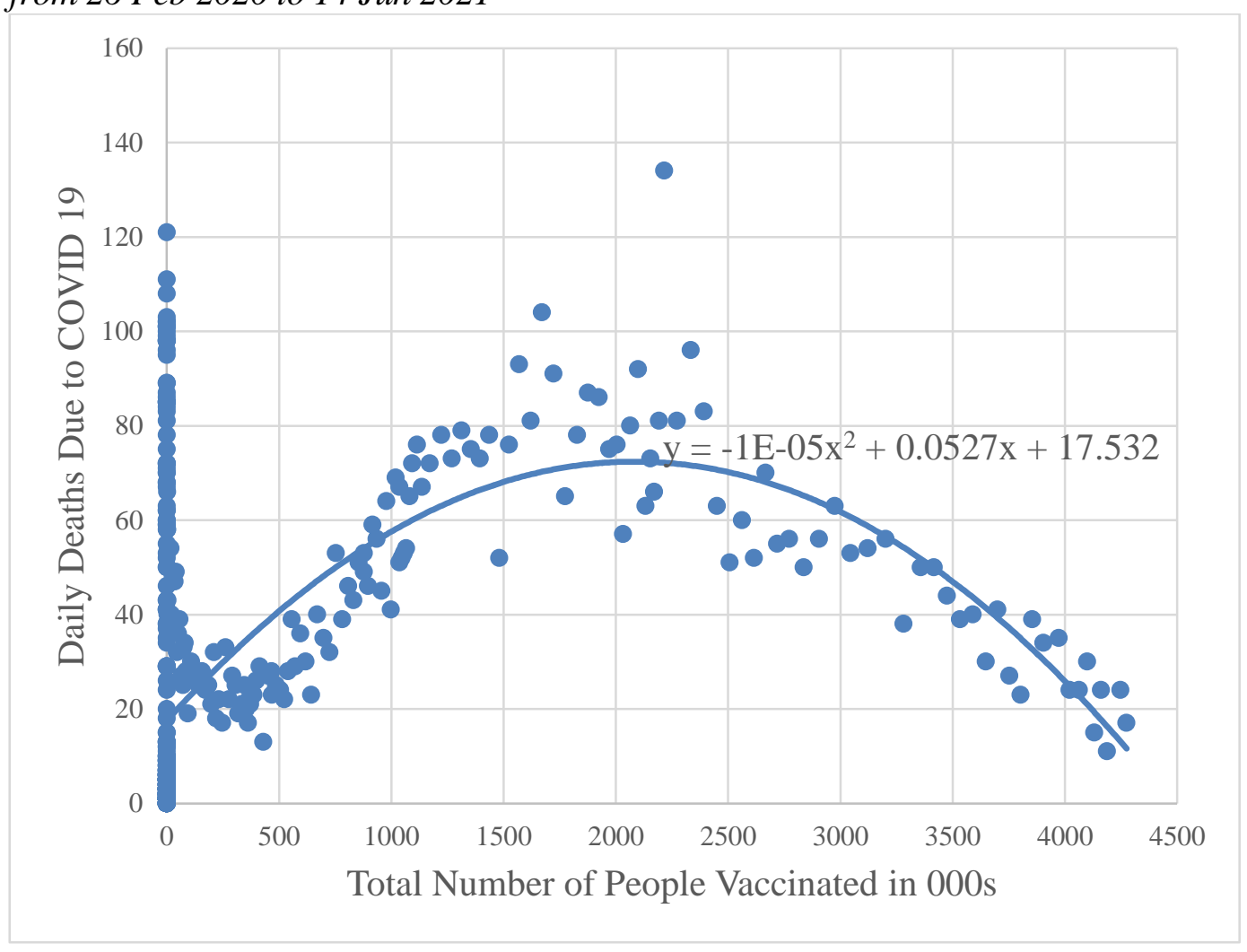

This evidence provides supportive evidence that vaccinations do work after a few weeks have passed. Thus, one expects that once a certain percentage of the population is vaccinated, then this might signal the end of the negative effect of the COVID-19 as measured by the daily number of deaths. This is exactly what many national authorities are hoping around the world. Once they have vaccinated the larger proportion of their population the disease will be eradicated. This is exactly what Figures 5 and 6 show. It can be estimated from both equations reported in the two graphs that if more than six million people are vaccinated, then the estimated 
number of daily deaths will be zero. This, and good weather might be the answer to cope with COVID-19. The good weather effect is examined in the following section.

\section{Temperature}

The last variable to be discussed is the role of weather temperatures. In Greece there is a high annual variability of weather temperatures as shown in Figure 7 in ${ }^{\circ} \mathrm{C}$. The variability can be very well approximated with a polynomial of third degree; the parameters of the equation are shown on the graph. However, there is great variability between the various regions of Greece, but here this paper has abstracted from regional differences in general; this can be the subject of another study. Instead, the average daily weather temperatures in the city of Athens were used as a crude indicator of the weather temperatures of Greece. Of course, it should be taken into account that almost half of the population of Greece is living in Athens and most of the daily deaths occurred in this city. In any case, one might safely assume that even though the average temperatures may differ between the different regions of Greece, their dispersion may be the same, and thus which area's temperature is used would not have affected the result.

Figure 7. Weather Temperatures from $26 \mathrm{Feb} 2020$ to 14 Jun 2021 in ${ }^{\circ} \mathrm{C}$

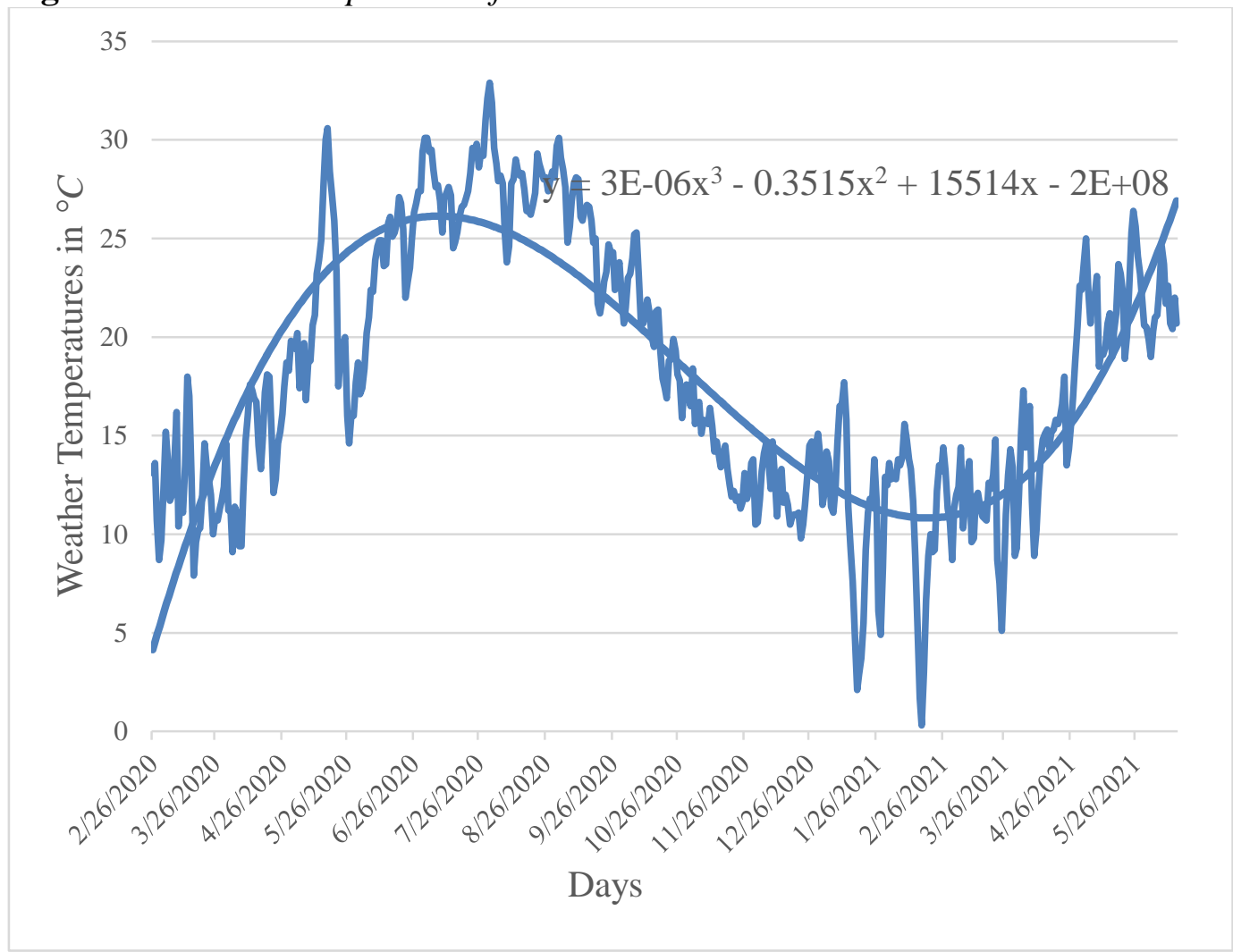


The average daily temperature during this period from 26 of February 2020 to 14 June of 2021 was $18^{\circ} \mathrm{C}$. The maximum average value was 32.9 degrees occurring on 31 of July 2021 and the minimum was 0.3 occurring on 16 of February 2021. The standard deviation of the weather temperatures was $6.69^{\circ} \mathrm{C}$.

Do weather temperatures affect the spread of the COVID-19 and therefore the number of deaths from it? Figure 8 shows the scatter diagram of the two variables. The linear effect (not shown in the graph) of temperature on the daily number of deaths is positive and actually very strong, but there are many dispersions.

A polynomial of second degree fits the relation better, and this is shown in Figure 2 along with the estimated parameters. In general, in the summer period, the number of deaths is reduced relative to the winter months. At relatively low average temperatures (below $15^{\circ} \mathrm{C}$ ), the relationship is flat or slightly positive. In these temperatures there is no effect on the number of deaths.

For temperatures higher than $15^{\circ} \mathrm{C}$, the number of deaths declines drastically, reaching almost zero for average temperatures above $25^{\circ} \mathrm{C}$. It is also interesting to note that for low temperatures (less than $8^{\circ} \mathrm{C}$ ), there was no day with zero deaths from COVID-19.

Figure 8. Weather Temperature and Deaths from COVID-19

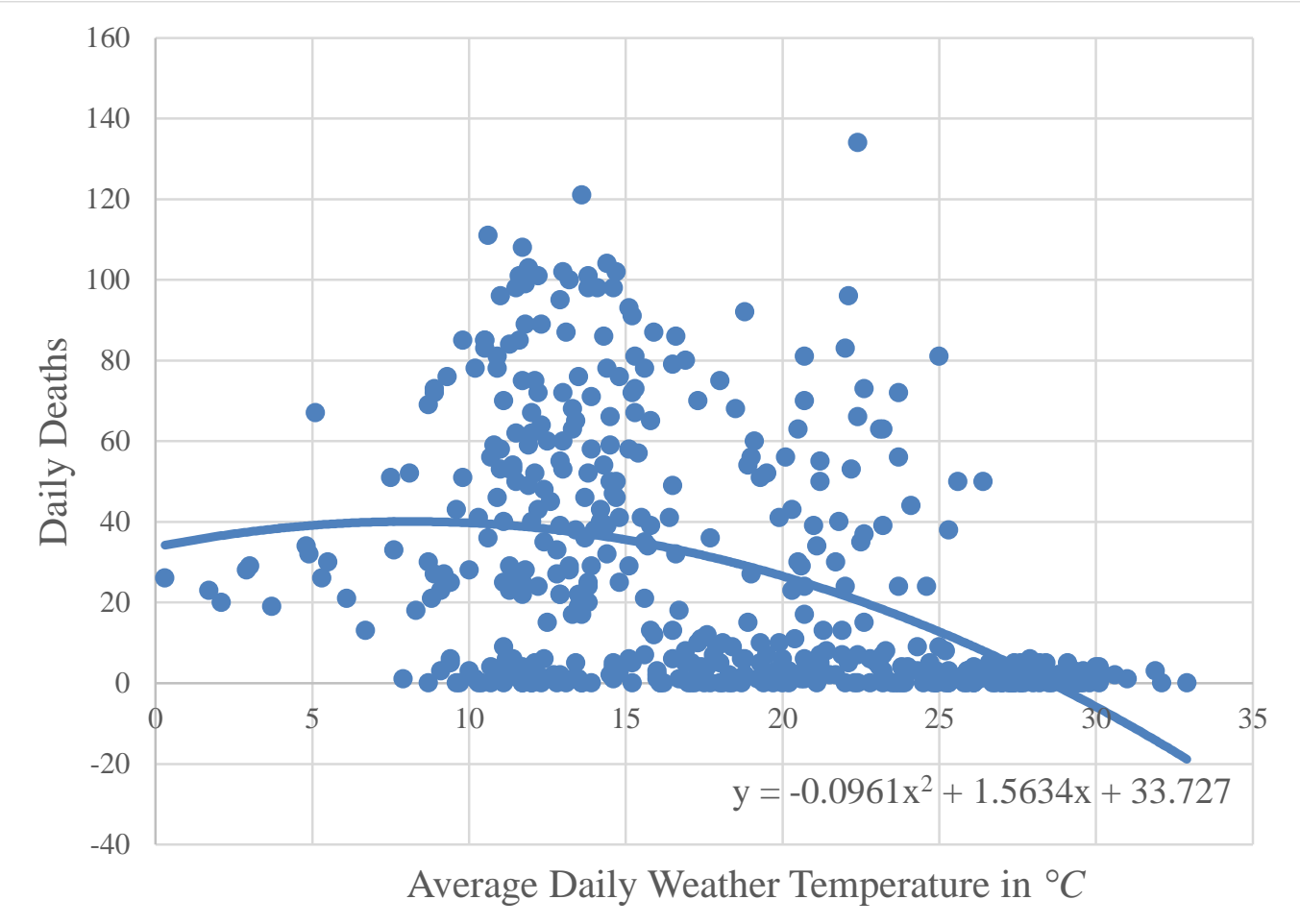

Note: Data on weather temperatures were retrieved from: http://www.meteoacharnes.gr/statis tika/datasummary.htm. [Accessed 15 June 2021]

Just as a demonstration from the second-degree polynomial, it can be calculated that for a temperature of $0^{\circ} \mathrm{C}$, the daily number of deaths is equal to 34 deaths. At the average of $18^{\circ} \mathrm{C}$, the daily number of deaths implied from the equation is 31 people. Solving the equation for zero deaths, a temperature of 
$28.5^{\circ} \mathrm{C}$ is sufficient. This exact temperature occurred three times in this period: 5 July 2020, 13 August 2020 and 3 September 2020. In the first, the number of deaths was zero, but in the other two cases the number of deaths were 2 per each day. It is important to repeat that the data of weather temperatures used in this study are from Athens, which are different from the rest of the country (usually lower). Even the Athens' data are the average of the day. Another weather temperature indicator would have been the standard deviations of the daily weather temperatures.

The correlation coefficient of the daily number of deaths and the average daily weather temperatures was -0.428 , implying a negative relationship. When temperatures increase, the number of deaths from COVID-19 decrease.

One may conclude from this descriptive evidence that weather temperatures did affect the daily number of deaths from COVID-19. The explanation given is that warm weather allows outdoor activities which reduce the spread of the disease.

\section{Conclusion}

The descriptive evidence shows that during lockdowns the number of deaths from COVID-19 do decrease after a certain time period, reversing an initial upward trend. From the three lockdowns, this was the case in the last two lockdowns. The first lockdown was implemented early on when the number of deaths were zero and therefore it had an immediate effect in preventing the number of deaths from rising.

The second conclusion relates to the total number of vaccinations and the total number of people vaccinated. The latter figure is lower because, with the exception of one vaccine, all others require two doses. Thus, the first figure includes people who have been vaccinated twice. The descriptive statistical evidence shows that initially the association between vaccinations and number of deaths was positive, but it quickly turned into a strong negative, indicating that vaccinations do work.

The last conclusion relates to weather temperature. The hypothesis that high weather temperatures reduce the infections and therefore the deaths from COVID19 is not falsified. At zero ${ }^{\circ} \mathrm{C}$, the daily number of deaths was found equal to 34 deaths. As temperatures increase, the number of deaths decrease. At $28.5^{\circ} \mathrm{C}$, the number of deaths was found to be equal to zero. Thus, an increase in vaccinations and temperatures are expected to eliminate the number of deaths from COVID-19 in Greece during the summer months of 2021.

The descriptive statistics presented in this paper by no means imply causality. Once this pandemic has done its cycle and more data become available, particularly on vaccinations, then a statistical model may explain and quantify the effects of the lockdowns, vaccinations and weather temperatures on the daily total number of deaths from COVID-19.

However, there appears to be some statistical problems which require attention. Firstly, it seems that the integration properties of the variables are not the 
same. Deaths is a variable which is integrated of order one while the other variables do not have the same level of integration. Thus, first differentiating might be an appropriate model. Secondly, the lagged effects should be determined because according to epidemiologists, measures, such as lockdowns and vaccinations, reduce deaths only after a long (in days) period has passed. These are important issues and a future research should account for them.

\section{References}

Adejare BO, Olaore GO, Udofia EE, Adenigba OA (2021) COVID-19 pandemic and business survival as mediation on the performance of firms in the FMCG-sector. Athens Journal of Business \& Economics, forthcoming. Retrieved from: https://www.athensjournals.gr/business/2021-4138-AJBE-Adejare-07.pdf. [Accessed 16 June 2021]

Bäckman G (2021) The outbreak of coronavirus (COVID-19) plagues in the world. Athens Journal of Social Sciences 8(3): 181-190. DOI=10.30958/ajss.8-3-2.

De Falco CC, Punziano G, Trezza D (2021) A mixed content analysis design in the study of the Italian perception of COVID-19 on twitter. Athens Journal of Social Sciences 8(3): 191-210. DOI=10.30958/ajss.8-3-3.

Güvercin D, Kesici AE, Akbaşlı S (2021) Distance education experiences of teacherparents during the COVID-19. Athens Journal of Education, forthcoming. https://www.athensjournals.gr/education/2021-4145-AJE-Kesici-05.pdf.

Jones P, Comfort D (2020) The COVID-19 crisis, tourism and sustainable development. Athens Journal of Tourism 7(2): 75-86. DOI=10.30958/ajt.7-2-1.

Jurić T (2021) Google trends as a method to predict new COVID-19 cases and sociopsychological consequences of the pandemic. Athens Journal of Mediterranean Studies, forthcoming. Retrieved from: https://www.athensjournals.gr/mediterranean/ 2021-4210-AJMS-Juric-05.pdf.

K1lıç ME (2021) What are the expectations of primary school teachers from instructional leaders during the distance education period? Athens Journal of Education, forthcoming. Retrieved from: https://www.athensjournals.gr/education/2021-4137AJE-Kilic-05.pdf. [Accessed 16 June 2021]

Marchetti G (2021) The management of the coronavirus emergency by the Italian government and the relationship between state and regions. Athens Journal of Law 7(2): 129-148. DOI=10.30958/aj1.7-2-1.

Mengu S, Mengu M, Gunay K (2021) Value-based communication during COVID-19 pandemic: a study on the twitter messages of Turkish Ministry of Health. Athens Journal of Mass Media and Communications 7(1): 23-44. DOI=10.30958/ajmmc.7$1-2$.

Osisanwo A (2021) "This virus is a common threat to all humans": discourse representation of COVID-19 in selected newspaper editorials. Athens Journal of Mass Media and Communications, forthcoming. Retrieved from: https://www. athe nsjournals.gr/media/2020-3719-AJMMC-Osisanwo-03.pdf. [Accessed 16 June 2021]

Papanikos GT (2020a) The demographics of COVID-19 in the European Union. Athens Journal of Social Sciences 7(4): 279-290. DOI=10.30958/ajss.7-4-4.

Papanikos GT (2020b) The impact of the COVID-19 pandemic on Greek tourism. Athens Journal of Tourism 7(2): 87-100. DOI=10.30958/ajt.7-2-2. 
Papanikos GT (2020c) Do national health expenditures matter for the COVID-19? Evidence from the European Union. Retrieved from: https://www.atiner.gr/gtp/ Papanikos(2020)-Health.pdf. [Accessed 16 June 2021]

Papanikos GT (2020d) The economic impact of the 2020 pandemic in the European Union. Retrieved from: https://www.atiner.gr/gtp/Papanikos(2020)-GDP.pdf. [Accessed 16 June 2021]

Papanikos GT (2021a) The European Union's recovery plan: a critical evaluation. Athens Journal of Mediterranean Studies 7(2): 85-102. DOI=10.30958/ajms.7-2-1.

Papanikos GT (2021b) Thucydides and the synchronous pandemic. Athens Journal of History 7(1): 71-94. DOI=10.30958/ajhis.7-1-4.

Parodi P, Maraglino F, Caraglia A (2021) The impact of COVID-19 epidemic on immunization activities in Italy. Athens Journal of Health \& Medical Sciences 8(1): 53-66. DOI=10.30958/ajhms.8-1-3.

Pinchbeck J, Heaney C (2021) Case report: the impact of online forum use on student retention in a level 1 distance learning module. Athens Journal of Education, forthcoming. Retrieved from: https://www.athensjournals.gr/education/2020-3962AJE-Pinchbeck-03.pdf. [Accessed 16 June 2021]

Uwah UE, Udoayang JO, UKlala PA (2021) Post COVID-19 and the acceptance of financial inclusion as a new normal in financial transactions: implications for Nigerian accountants and other financial service providers. Athens Journal of Business \& Economics, forthcoming. Retrieved from: https://www.athensjournals.gr/ education/2020-3962-AJE-Pinchbeck-03.pdf. [Accessed 16 June 2021]

Uysal B, Yorulmaz M, Demirkıran M, Ulusinan E (2020) The assessment of sociopsychological effects of COVID-19 on Turkish people. Athens Journal of Health \& Medical Sciences 7(4): 235-252. DOI=10.30958/ajhms.7-4-4. 
